\title{
A Methodological Strategy for Reimagining Development: Enabling Complex Systemic Patterns to Surface through Multiple Voices
}

\section{Danny Burns}

\begin{abstract}
The Reimagining Development initiative pursued a methodological strategy that viewed emerging development issues through multiple perspectives; juxtaposed different sets of issues; tested the resonance of narratives across multiple sites of engagement; drew new boundaries around key problems; and generated questions to pursue elsewhere. It was an attempt to use a systems approach to get a less partial picture of a large and complex system. This article describes such approaches generally, their strengths and limitations, and reflects on their application to the Reimagining Development initiative.
\end{abstract}

\section{Introduction}

This article discusses the methodological principles which underpin the Reimagining Development initiative. It links the work of the initiative with an emerging methodological discourse on systemic approaches to Action Research. Over the past decade my own work has centred on developing 'systemic action research' processes (Burns 2007). This has involved designing learning architectures which can provide meaningful insight into change across large systems - by which I mean a whole organisation (e.g. an international NGO); a country programme; a global supply chain; an inner city informal settlement; a network of small towns, etc. The reason for developing these methods is rooted in a familiar research conundrum: while qualitative case studies, detailed ethnographies, and localised action research help to explain how and why things happen, they lack the breadth necessary for a macro picture of what is happening. Most quantitative research, on the other hand, offers breadth, and in its identification of patterns offers clues to explanation, but usually cannot explain the how and the why. Systemic action research provides a vehicle for allowing the detail of the micro level engagement to be built into a larger macro narrative. While this methodology was not explicitly built into the Reimagining Development initiative, there are sufficient parallels to reflect on it from the methodological perspective of a systemic action research process.

\section{Systemic approaches}

Systemic approaches are important because they tell us that the issues that we are engaged with are always enmeshed with other issues; that there are meta-level patterns and norms which affect these issues; that our assessment of them is often dependent on where we place the boundaries of what we view and that unintended consequences can emerge from the inter-relationships. Systemic approaches are particularly relevant to the analysis of the effects of a system-wide shock such as the global economic crisis of 2008-10. In a context of global crisis such as this, it is not enough just to look at particular aspects or cases of impact in isolation: they are intrinsically connected to the other elements of the system which surround them. One way of looking at the Reimagining Development initiative is as an attempt to view contemporary development through multiple lenses, and from this multiple perspective to explore where new visions of development might lie. 
There are a number of methodological principles which can be drawn from this perspective which apply to the Reimagining Development initiative:

- The need to see the system from across multiple perspectives

- The juxtaposition of different sets of issues, often treated separately from each other

- 'Resonance testing' across multiple points in a system

- Drawing different system boundaries around the problems we are trying to resolve

- Generating questions to seed into other parts of a system.

\section{Seeing the system through multiple perspectives}

Reimagining Development attempted to reflect on the state of development from a wide range of geographical, social, political, institutional and economic starting points. In systemic action research it is considered important to build a picture of the systems being explored from multiple starting points because:

- Any system is constructed of relationships. People and organisations within systems have vested interests and perspectives which shape what is possible and what is not, so that the relationships within a system are always mediated by power. Unless we understand the system from multiple perspectives we cannot begin to understand the complexity of the power relationships. The Reimagining Development initiative dealt with the power differentials within aid relationships by balancing explorations of the perspectives of aid donors, development practitioners and private sector actors against those of Kutchi villagers in Gujarat, indigenous people in the Amazon, citizens of Malawi, Ethiopia and elsewhere - groups whose views on the practices and meanings of aid and development tend to be muted.

- Through inquiry in multiple places we can see patterns which run across the system. Stories which are played out in one part of the system can be tested for their resonance in other parts of the system. That people in the Gujarat, Ethiopian and other diverse sites experienced the crisis not as a shock but as 'crisis as usual' signalled a shared set of experiences of development. It suggested both that the preceding period of boom had failed to deliver what many people viewed as significant improvements in wellbeing, but also that the experience of crisis was routine enough for its global dimensions to have failed to impress. At the same time, a sense of a system no longer fit for purpose (even if in the views of some, it had never worked well) emerged clearly across many of the sites.

The solutions to problems often exist outside of the system boundaries of the localised problem; understanding the macro dynamics of a system can sometimes yield insights into how an intervention in one domain can have a significant impact in another. The ActionAid case study (Ho, this IDS Bulletin) highlights how an NGO is struggling to be accountable to the people it is working with (by asking 'will our work increase their agency?') while coping with the increased demand for accountability to taxpayers in donor countries.

Allowing space for the unexpected to emerge is an important feature of the process of systemic action research. Drawing on a wide range of sites without imposing a restrictive rationale on them, or pre-identifying connections between them, is crucial to ensuring diversity of perspective; it also mitigates against issues being framed exclusively through the lenses of the dominant perspectives. The design of the Reimagining Development initiative explicitly aimed for a wide and deliberately diverse set of locations and people. The rationale for this selection strategy was not to achieve some approximation of representativeness of the development system (which would be impossible), but precisely to create space in which alternative new perspectives might find room to emerge.

\section{The juxtaposition of one set of issues against another}

The various issues that are addressed in the different Reimagining Development sites allows us to consider diverse parts of the development agenda in relation to each other, creating the possibility of unusual juxtapositions and insights. This is akin to the creation of a collage of perspectives. It is through the construction of an 'inquiry collage' that unexpected possibilities to reimagine are opened up and a more varied overall picture emerges: 
One of [the collage's] greatest strengths is that it can be used as a collaborative process in which individuals bring their own fragments and connect them with an emergent representation. One way of creating an inquiry collage is for participants to work alone to build their part of the picture and then to juxtapose their work against the work of others ... the narrative of collage is not linear. If change does not occur in linear causal lines, then it seems obvious to me that good explanation will not be entirely linear. This does not mean that a linear narrative is unhelpful, but that it is only one way of generating insight. (Burns 2007: 118)

An open, exploratory inquiry process of the kind aspired to by the Reimagining Development exercise needs to allow space to juxtapose different dimensions, the connections between which may not be obvious. The relationships between elements of a system - in this instance, different locations and social groups within the development system - may not be linked in a simple causal relationship, but there may be complex reciprocal relations through which they connect. Sometimes these connections only emerge when we juxtapose elements unexpectedly. For example, several articles point out that the response to falling off the growth train is not simply to get back on it, but instead to focus on things that will better direct future growth towards development such as social relations (Mehta, this IDS Bulletin), inequality (Pollard et al., this IDS Bulletin), exclusion (Shankland, this IDS Bulletin) and slowing down of transactions (McCulloch, this IDS Bulletin).

\section{Drawing different system boundaries around the problem}

One of the key elements in any process of reimagining is drawing different boundaries to those that we normally construct around the issues we are engaging with. We might, for example, look at commodity transactions only in terms of their implications for the economy. As soon as we widen the boundaries to include the environment then the whole picture looks different. The Crisis Watch article (McGregor, this IDS Bulletin) noted that an emphasis on resilience to crises failed to recognise the costs this resilience entailed for social reproduction. Similarly, if we see governance as limited to what happens in the formal arena then the possibilities for change might appear to be limited, but if we see it as about the relationship between the formal and the informal then a whole new world of possibilities opens out. For example, an application of the Amazon (Shankland, this IDS Bulletin) case study perspective on the role of informal governance to the analysis of the Ukraine social welfare system (Berenson, this IDS Bulletin) might have revealed more ferment in the system as a result of the crises than the formal analysis did. Drawing the boundaries differently allows us to reimagine possibilities for development.

\section{Resonance testing across multiple points in a system}

Building the types of learning architecture that I have described - which allow rich qualitative and participatory data to generate macro-level patterns - cannot be based on the core principle of representativeness that underpins much research work (for the case of Crisis Watch, see McGregor, this IDS Bulletin). This is firstly because it would hardly be possible to create the same numbers of qualitative cases, and secondly because their characteristics do not provide an adequate basis of comparison for explanation. So instead, architecture needs to be built which is based on the ideas of resonance. This is more efficient because it does not require every case to be examined, and gets more quickly to what is important.

Resonance testing involves inquiry in many different places. This allows us to see what issues emerge and then take those issues into the other to see if they are resonant. If they are resonant, people will continuously bring new stories to speak to the stories that have already been told. If they continue to be resonant across the inquiry system, we can take them into places beyond that system to see if the issues remain resonant across boundaries. This is a powerful process of triangulation.

\section{Where next?}

The potential strength of the inquiry represented by the Reimagining Development initiative is not so much that it is yet able to reimagine development, as that it surfaces the key questions for development which may make such reimagination possible. A close analysis of the patterns that run across this programme will reveal many of these emergent questions. This 
will allow us to set an agenda for deeper crosssite research which has the potential for genuinely reframing our view of what development is and can be.

The Reimagining Development initiative has surfaced some key insights into the varied concerns, perceptions and debates about development in the wake of a financial crash that may (or may not yet) have changed all the rules. Yet the message that comes across clearly from

\section{Reference}

Burns, D. (2007) Systemic Action Research: A

Strategy for Whole System Change, Bristol: Policy

Press across these varied settings is that arriving at new goals and thinking about development processes that counter long-held orthodoxies, assumptions and institutional interests takes time; at present there are more questions than there are answers, and the patterns and connections between them are not always evident yet. This process of reimagining needs to be seen as ongoing, with Reimagining Development only the first step. 